\title{
Validation of Self-Reported Anthropometrics in Female College Freshmen
}

\author{
RYAN J. LEONE ${ }^{1,2}$, AMY L. MORGAN $¥ 1$, and MARY-JON LUDY‡2 \\ ${ }^{1}$ School of Human Movement, Sport, and Leisure Studies, Bowling Green State \\ University, Bowling Green, OH USA; ${ }^{2}$ Department of Public and Allied Health, \\ Bowling Green State University, Bowling Green, OH USA
}

†Denotes graduate student author, ‡Denotes professional author

\begin{abstract}
International Journal of Exercise Science 9(1): 47-55, 2016. Most investigations concerning the validity of self-reported anthropometrics focus on weight, height, and body mass index. This study extends those investigations by exploring the impact of self-reporting bias on the disease risk indicators of waist circumference and body fat percentage. Female college freshmen $(n=128)$ self-reported weight and height, then underwent measurements for weight, height, waist circumference, and body fat percentage. Self-reporting bias was defined as selfreported minus directly-assessed anthropometric value. Despite no differences in self-reported versus directly-assessed weight or height for the total group, students with high waist circumference and excess fat under-reported their weight by $2.3 \pm 4.4 \mathrm{lb}(\mathrm{p}<0.05)$. Self-reporting bias was negatively correlated with waist circumference $(r=-0.362 ; p<0.001)$ and body fat percentage $(\mathrm{r}=-0.317 ; \mathrm{p}<0.001)$. Although many female college freshmen accurately represent their weight, those with excess fat and waist circumference under-reported their weight. This may lead to missed opportunities for risk identification, prevention, and intervention.
\end{abstract}

KEY WORDS: Body mass index, obesity, waist circumference, women's health, young adult

\section{INTRODUCTION}

Self-reported anthropometric data is convenient and inexpensive, but relying on this data requires an accurate estimation of weight and height. Data consistently demonstrate under-reporting of weight and over-reporting of height $(8,12)$. Underreporting of weight occurs particularly among women $(2,8,9,15,23)$ and overweight/obese individuals $(2,8,12,15$, $23,26,28)$. Conversely, height tends to be over-reported, regardless of sex (8).
Since young women transitioning to the university setting are particularly vulnerable for weight gain (31), they are a population of interest for health-related studies. Self-reported anthropometric data is often used in order to reach a larger sample or due to poor equipment mobility. However, this may lead to an underestimation of overweight/obesity prevalence and associated disease risk. Although body mass index (BMI; $\mathrm{kg} / \mathrm{m}^{2}$ ) is a commonly used proxy for body fatness, individuals may be classified as healthy when they actually have unhealthy levels of 
body fat $(21,27)$ - a misclassification which occurs especially in the normal and overweight BMI categories (13).

It is thus important to use more accurate indicators of disease risk whenever possible. Previous studies have primarily focused on BMI and demographics, such as race and age, as predictors of self-reporting error. To date no studies have extended this research to explore associations with more accurate risk markers, such as WC and body fat percentage ( $\%$ fat). In women, BMI and WC increase by $0.4 \%$ annually, with the greatest increases among those aged 18 to 39 years (18). This is particularly concerning, given that costs of overweight/obesity are also higher in women (10). Identification of individuals, specifically women, at risk for overweight/obesity may help to offset these costs. This study contributes to the growing body of research by 1) determining the degree of accuracy between self-reported and directly-assessed anthropometrics in female college freshmen, as well as 2) examining the relationship between these biases and more accurate indicators of disease risk.

\section{METHODS}

\section{Participants}

As part of a larger study examining patterns and composition of weight change in college freshmen conducted in 2012-2014, participants were asked to complete a selfadministered demographic questionnaire soliciting age, race/ethnicity, scholastic major, weight in pounds, and height in inches during the testing visit. In total, 147 first-year, female students at a large, Midwestern university were recruited via public advertisements, classroom announcements, and welcome week activities. Students were eligible to participate if they met the following criteria: on-campus residence, age $\geq 18$ years, non-claustrophobic, non-pregnant, $\leq$ $250 \mathrm{~kg}$ (scale capacity), and no implanted medical device(s). Participants were aware they were to undergo anthropometric measurements during the testing visit. Since an elevated body temperature or breathing rate post-exercise, or presence of food and/or beverages in the gastrointestinal tract may influence the accuracy of results (e.g., overhydration would falsely reduce body fat percentage) (16), participants were instructed to refrain from exercise and eating/drinking anything other than water within two hours of their scheduled testing visit.

\section{Protocol}

Following completion of the demographic questionnaire, participants changed into compression clothing and a Lycra swim cap provided by researchers; shoes, socks, jewelry, and/or hair accessories were removed prior to testing to minimize air trapping. Measurements included weight, height, WC, and $\%$ fat.

Height was measured with a wallmounted, calibrated stadiometer. Participants stood with their backs touching, but not leaning against the device. Feet were placed in the outline on the base plate and researchers verified the participant's head was positioned in the Frankfort plane. The head plate was lowered to touch the top of the participant's head, without undue pressure, and measurement was recorded to the nearest $0.1 \mathrm{~cm}$. 
WC was measured using a retractable tape placed immediately superior to the iliac crest, approximately at the navel line (25). Measurements were taken with the tape parallel, recording the measurement to the nearest $0.1 \mathrm{~cm}$.

Body composition was assessed using airdisplacement plethysmography (ADP) via BODPOD (Cosmed USA, Concord, CA), according to standard procedures (22). Body fat was estimated to the nearest $0.1 \%$ using the Siri equation (29) for Caucasian and Hispanic participants and the Brozek equation (5) for African Americans. Prior to entering the testing chamber, weight was obtained using the calibrated scale coupled with the BODPOD and recorded to the nearest $0.1 \mathrm{~kg}$.

Data were collected during the first three weeks on campus and written informed consent was obtained from all participants at the beginning of their test visit. Participants received $\$ 5$ in campus spending money and another small item (i.e., reusable grocery bag or Frisbee). The university's institutional review board approved this study.

\section{Statistical Analysis}

Directly-assessed weight, height, and WC were converted from metric to imperial units $(1 \mathrm{~kg}=2.2 \mathrm{lb} ; 1 \mathrm{~cm}=0.39 \mathrm{in})$ and rounded to the nearest whole number. BMI was calculated as weight (lb) / height ${ }^{2}$ (in) * 703. The differences between self-reported and directly-assessed weight, height, and BMI were compared via paired sample ttests. Self-reporting biases of weight, height, and BMI were calculated as selfreported minus directly-assessed values for each variable. Pearson correlation coefficients were conducted to identify associations between self-reported and directly-assessed anthropometric values, as well as to identify relationships among selfreported weight bias with WC and \% fat.

Participants were dichotomized into groups who under-reported their weight (i.e., selfreported - directly-assessed < 0) (underreporter group) and those who reported accurately or over-reported (i.e., selfreported - directly-assessed $\geq 0$ ) (accurate/over-reporter group). Accurate- and overreporters were grouped together due to the reduced propensity for health risk among the members in this group of relatively healthy females. Independent samples $\mathrm{t}$ tests were used to compare weight, BMI, $\mathrm{WC}$, and \% fat among these groups.

Sensitivity was calculated as the ability of the self-reported anthropometric data to correctly classify participants as overweight/obese based on directlyassessed BMI. Specificity was calculated as the ability of the self-reported anthropometric data to correctly classify normal weight participants as normal weight based on directly-assessed BMI. Positive predictive value was calculated as the proportion of the amount of "true positives" (i.e., self-reported overweight/obese and directly-assessed overweight/obese) to all positives (i.e., true positives + false positives). Negative predictive value was calculated as the number of "true negatives" (i.e., selfreported normal weight and directlyassessed normal weight) to all negatives (i.e., true negatives + false negatives). Cohen's $\mathrm{k}$ was calculated to identify level of agreement between self-reported and directly-assessed BMI. 
Table 1. Anthropometric data for all participants, under-reporters, and accurate- or over-reporters.

\begin{tabular}{|c|c|c|c|c|}
\hline & $\begin{array}{l}\text { SR } \\
\text { Mean (SD) }\end{array}$ & $\begin{array}{l}\text { DA } \\
\text { Mean (SD) }\end{array}$ & $\begin{array}{l}\text { SR Biasa,b } \\
\text { Mean (SD) }\end{array}$ & $p^{c}$ \\
\hline \multicolumn{5}{|c|}{ All Participants $(\mathrm{n}=128)$} \\
\hline Weight (lb) & $140.6(33.0)$ & $140.7(34.6)$ & $-0.1(4.4)$ & 0.824 \\
\hline Height (in) & $64.7(2.8)$ & $64.6(2.5)$ & $0.2(1.3)$ & 0.137 \\
\hline $\operatorname{BMI}\left(\mathrm{kg} / \mathrm{m}^{2}\right)$ & $23.6(5.0)$ & $23.7(5.4)$ & $-0.1(1.2)$ & 0.217 \\
\hline WC (in) & & $32.0(4.8)$ & & \\
\hline Fat $(\%)$ & & $28.8(8.1)$ & & \\
\hline \multicolumn{5}{|c|}{ Under-Reporters (self-reported weight bias $<0 ; n=35$ ) } \\
\hline Weight (lb) & $151.8(51.3)$ & $157.0(52.0)^{\mathrm{d}}$ & $-5.3(4.2)$ & $<0.001$ \\
\hline Height (in) & $64.8(3.1)$ & $64.7(2.9)$ & $0.1(1.0)$ & 0.609 \\
\hline BMI $\left(\mathrm{kg} / \mathrm{m}^{2}\right)$ & $25.3(7.6)$ & $26.3(8.3)^{d}$ & $-1.0(1.5)$ & $<0.001$ \\
\hline WC (in) & & $34.3(6.7)^{\mathrm{d}}$ & & \\
\hline Fat $(\%)$ & & $31.7(9.7)^{\mathrm{d}}$ & & \\
\hline \multicolumn{5}{|c|}{ Accurate- or Over-Reporters (self-reported weight bias $\geq 0 ; n=93$ ) } \\
\hline Weight (lb) & $136.4(21.7)$ & $134.5(22.0)^{\mathrm{d}}$ & $1.9(2.4)$ & $<0.001$ \\
\hline Height (in) & $64.7(2.7)$ & $64.5(2.4)$ & $0.2(1.4)$ & 0.164 \\
\hline BMI $\left(\mathrm{kg} / \mathrm{m}^{2}\right)$ & $22.9(3.4)$ & $22.7(3.4)^{\mathrm{d}}$ & $0.2(0.9)$ & 0.038 \\
\hline WC (in) & & $31.1(3.5) \mathrm{d}$ & & \\
\hline Fat (\%) & & $27.7(7.1)^{\mathrm{d}}$ & & \\
\hline \multicolumn{5}{|c|}{$\begin{array}{l}\text { SR }=\text { self-reported, DA = directly-assessed, } \mathrm{BMI}=\text { body mass index, } \mathrm{WC}=\text { waist circumference. a SR Bias } \\
=\mathrm{SR}-\mathrm{DA} .{ }^{\mathrm{b}} \text { Negative values indicate under-reporting. }{ }^{~} \text { Significant differences }(\mathrm{p}<0.05) \text { between } \mathrm{SR} \text { and } \\
\mathrm{DA} \text { are bolded. Comparisons between } \mathrm{SR} \text { and DA are based on paired samples } t \text {-tests. }{ }^{\mathrm{d}} \text { Significant } \\
\text { differences }(\mathrm{p}<0.05) \text { between under-reporters and accurate- or over-reporters. Comparisons between } \\
\text { under-reporters and accurate- or over-reporters are based on independent samples } t \text {-tests. }\end{array}$} \\
\hline
\end{tabular}

The following cut-points were used: BMI $\geq$ $25 \mathrm{~kg} / \mathrm{m}^{2}$ (National Institutes of Health $(\mathrm{NIH})$ ) standard cut-point for overweight (25), WC > 35 in (NIH standard cut-point for disease risk based on WC (25), and body fat $\geq 33 \%$ (based on a multiple regression model equating BMI $\geq 25 \mathrm{~kg} / \mathrm{m}^{2}$ to body fat $\geq 33 \%$ in 283 young adult women (14). Analyses were performed using IBM SPSS Statistics Version 22.0 (IBM Corporation, Armonk, NY). A two-tailed alpha level of $\mathrm{p} \leq 0.05$ was used to indicate significance. Alpha levels between 0.05 and 0.10 were considered trends worthy of further investigation.

\section{RESULTS}

Nineteen participants did not provide complete data (i.e., left self-reported height and/or weight blank on demographic questionnaire) and were thus excluded from analyses, resulting in a total of 128 participants aged $18.1 \pm 0.4$ years. There was no difference in directly-assessed weight, height, BMI, WC, or $\%$ fat ( $p>0.05$ for all) between excluded individuals and participants. The majority of participants were Caucasian $(\mathrm{n}=108 ; 84.4 \%)$, with the remainder Black/African American ( $\mathrm{n}=15$; $11.7 \%)$ and Hispanic $(n=5 ; 3.9 \%)$. The sample mirrors the racial/ethnic background of the campus $(85.6 \%$ Caucasian/other, $\quad 10.7 \%$ Black/African American, and 3.7\% Hispanic) (3). In terms of major, $45.3 \%$ of participants were health majors $(n=58)$ while $54.7 \%(n=70)$ were nonhealth majors. According to directlyassessed BMI, $4.7 \% \quad(\mathrm{n}=6) \quad$ were underweight, $68.8 \% \quad(\mathrm{n}=88)$ were normal weight, $18.0 \% \quad(n=23)$ were overweight, 
$5.5 \%(n=7)$ were obese class I, $1.6 \%(n=2)$ were obese class II, and $1.6 \%(n=2)$ were obese class III. Using the BMI cut point of $25 \mathrm{~kg} / \mathrm{m}^{2}$ to indicate disease risk, $26.6 \%$ $(\mathrm{n}=34)$ were classified as overweight/obese. Elevated WC was identified in $18.8 \%(\mathrm{n}=24)$ of participants while $25.0 \% \quad(n=32)$ had excess $\%$ fat (determined by ADP).

There was no overall difference between self-reported and directly-assessed anthropometric data for any variable (Table 1) when all participants were considered. Using a cut-off of $5 \mathrm{lb}$ to classify accurate reporting (6), weight was accurately reported in $84.4 \%(n=108)$ of participants. Weight was under-reported in $10.2 \% \quad(n=13)$ of participants and over-reported by in $5.5 \%(\mathrm{n}=7)$ of participants. When classified by BMI, weight was under-reported ($2.0 \pm 4.4 \mathrm{lb} ; \mathrm{p}=0.014)$ in participants with BMI $\geq 25 \mathrm{~kg} / \mathrm{m}^{2}$ leading to subsequent underestimation of self-reported BMI ($\left.0.6 \pm 1.4 \mathrm{~kg} / \mathrm{m}^{2} ; \mathrm{p}=0.022\right)$. When classified by WC, participants who had high WC also under-reported their weight $(-2.3 \pm 4.4 \mathrm{lb}$; $\mathrm{p}=0.018$ ), however differences in BMI did not achieve statistical significance. When classified by $\%$ fat, those with excess fat $(>33 \%)$ under-reported their weight ($2.3 \pm 4.4 \mathrm{lb} ; \mathrm{p}=0.007)$, resulting in a trend towards an underestimation of selfreported BMI $\left(-0.5 \pm 1.5 \mathrm{~kg} / \mathrm{m}^{2} ; \mathrm{p}=0.056\right)$. There was no difference between selfreported and directly-assessed anthropometrics in participants with healthy BMI, WC, or \% fat. Differences in self-reported and directly-assessed height did not achieve significance in any group, nor was there a difference between any selfreported and directly-assessed anthropometric value in health and nonhealth majors.
There were strong, positive correlations between self-reported and directly-assessed weight, height, and BMI for all participants, as well as when under-reporters and accurate-/over-reporters were analyzed separately $\quad(r \geq 0.859, \quad p<0.001$ for all). Moderate negative correlations were observed between self-reported weight bias and $\mathrm{WC}(\mathrm{r}=-0.362 ; \mathrm{p}<0.001)$ and $\%$ fat $(\mathrm{r}=-$ $0.317 ; \mathrm{p}<0.001)$ as depicted in Figure 1. Selfreported and directly-assessed weight, height, BMI, and self-reporting bias of all participants are presented in Table 1.

Compared to those who accurately- or over-reported their weight, individuals who under-reported their weight weighed more $(+22.5 \mathrm{lb})$ and had a greater BMI $(+3.5$ $\left.\mathrm{kg} / \mathrm{m}^{2}\right)$, WC (+3.2 in), and \% fat (+4.0\%) (Table 1; $<<0.05$ for all). Height did not vary significantly between groups. Sensitivity, representing the proportion of self-reported overweight/obese (via BMI) students who were indeed overweight/obese, was $94.1 \%$. Specificity, representing the proportion of self-reported normal/underweight (via BMI) students who were correctly identified as normal/underweight using directly-assessed values, was $97.9 \%$. Positive predictive value, the probability that self-reported overweight/obesity (via BMI) truly indicates overweight/obesity, was $94.1 \%$. Negative predictive value, the probability that self-reported normal/underweight truly indicates normal/underweight (via BMI) was $97.9 \%$. There was almost perfect agreement between self-reported and directly-assessed weight indicated by $\mathrm{\kappa}=0.92$. 

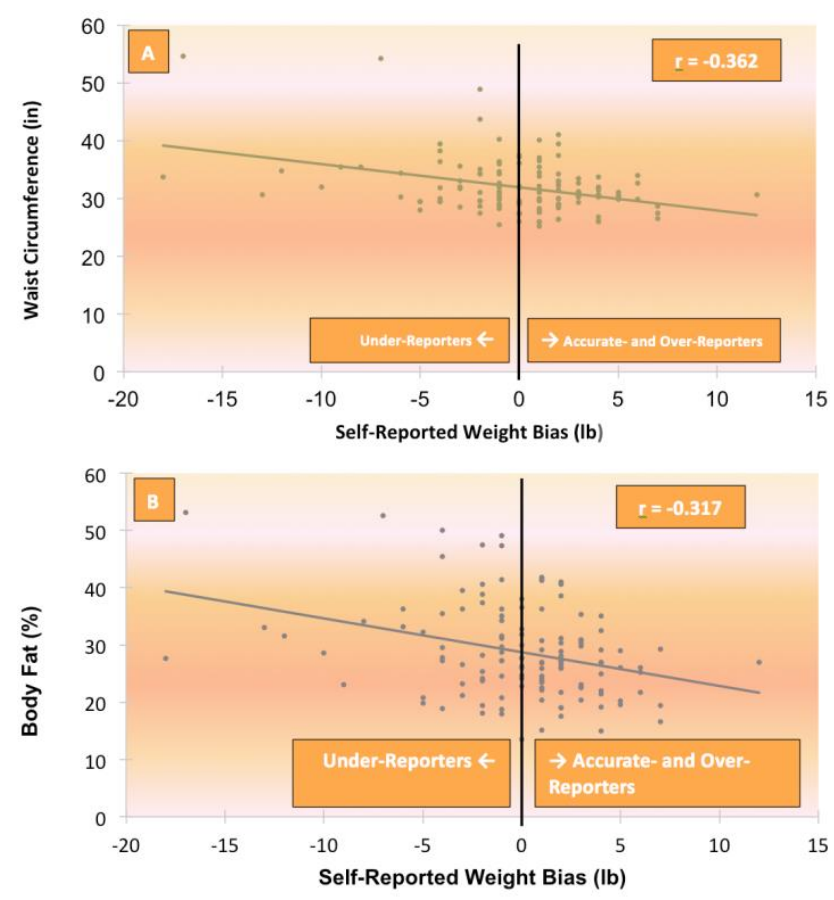

Figure 1. Scatterplots depicting the relationship between self-reported weight bias (self-reported directly-assessed weight) and (A) waist circumference and (B) body fat percentage. Analyses were performed using Pearson correlation coefficients ( $\mathrm{p}<0.001 ; \mathrm{n}=128$ for both).

\section{DISCUSSION}

This study sought to determine the degree of accuracy between self-reported and directly-assessed anthropometrics in female college freshmen as well as examine the relationship between self-reporting biases and other indicators of disease risk (i.e., WC and $\%$ fat). The results of the present study demonstrate very strong positive correlations between self-reported and directly-assessed weight, height, and BMI. Overall, there was a high level of agreement between self-reported and directly-assessed weight $(-0.1 \mathrm{lb})$, height $(+0.2 \mathrm{in})$, and BMI $\left(-0.1 \mathrm{~kg} / \mathrm{m}^{2}\right)$. This was unexpected as women typically underreport their weight $(2,9,15,17,23)$ anywhere from $-0.4 \mathrm{lb}$ to $-7.7 \mathrm{lb}$ (12). In female college students specifically, other studies found height to be over-reported by +0.5 in (19) and +1.1 in (9) and weight to be under-reported by $-4.2 \mathrm{lb}(9)$ and $-7.5 \mathrm{lb}$ (19). However, both of these studies measured participants' weight wearing light clothing and without indication of instruction on how to report their weight (i.e., light clothing, with or without shoes, etc.), perhaps contributing to reporting error. Nevertheless, the high overall level of agreement between self-reported and directly-assessed anthropometrics in the present study is a novel finding.

The high sensitivity (94.1\%) suggests the use of self-reported anthropometrics indeed captures actual cases of overweight/obesity. This finding corroborates with previous studies in both adults $(1,6)$ and older adolescents (4). However, some prior studies demonstrated sensitivities of $48 \%$ (19) to $52 \%$ (11). In both of these studies, participants were unaware they were to be weighed, while in the present study, participants were aware their weight would be measured. This may have contributed to reporting accuracy as it has been suggested that the expectation of being weighed results in more precise selfreported weight (7); however, Nawaz et al. (26) found that although overweight/obese, middle-aged adult female participants were told they would be weighed, weight was still under-reported. It is unlikely that the age of our sample impacted reporting behavior as previous work has established that women under-report their weight across the lifespan (23).

This study was unique in that it examined other indicators of overweight/obesity and disease risk in addition to BMI. Previous studies have determined that increases in 
weight and/or BMI coincide with increases in the degree of under-reporting $(1,2,8,12$, 19, 23, 26). Similar tendencies were observed in the present study; weight was under-reported to a greater extent when WC and \% fat were higher. Moreover, individuals who under-reported their weight had significantly higher weight, BMI, WC, and \% fat than those who accurately- or over-reported their weight. When dichotomized by WC and \% fat, individuals with abdominal obesity significantly under-reported their weight, as did individuals with excess fat. It is unclear whether under-reporting one's weight is intentional, resulting from social desirability or unintentional due to lack of knowledge regarding one's current weight status. Additionally, weight gain is not uncommon during transition to the university (31). Previous data indicate that female freshmen gain $2.9 \mathrm{lb}$ during their first 10 to 12 weeks on campus (20). Therefore, it is possible to have gained weight during the first three weeks (i.e., during the measurement period) resulting in an unintentionally under-reported weight.

Several limitations must be noted. This study used a convenience sample as it was part of a larger project. It was advertised as a health-related study and thus more health-conscious individuals may have participated, partially explaining the accuracy of self-reported weights. However, there were no significant differences between health and non-health majors. Incomplete data from 19 participants and failure to acknowledge when and where (e.g., home, physician, gym) participants last weighed themselves were other limitations. Participants were also not instructed on how to report their weight (e.g., light clothing, without shoes). Finally, the generalizability of the findings may be limited to female university students and future research in other, less educated populations is warranted.

These findings suggest that individuals at greater disease risk are more likely to under-report their weight - a finding that complements previous studies using BMI only. Older adolescents do not perceive themselves to be at risk (24) and it is common for overweight/obese individuals to underestimate their weight as a health risk (30). Thus, susceptible female freshmen may not engage in health-promoting behaviors. Misclassification of overweight/obese individuals as maintaining a healthy weight may further decrease the likelihood of participating in weight control practices (19). As young adults entering college begin to establish lifelong behaviors, practitioners in this setting are in a unique position to intervene and mitigate disease risk. Early identification may lead to lifestyle modifications and reduced risk of chronic disease (24). However, reliance on inaccurate reports of anthropometric data may prevent identification of at-risk individuals. The current findings, as well as previous work $(12,19)$, support the recommendation that, aside from surveillance data, direct assessment should be used whenever possible.

Given the high sensitivity, correlation, Cohen's $\mathrm{K}$, and overall reporting accuracy, our results suggest that self-reported anthropometrics are an acceptable substitution for objective data in female college freshmen when measurement is not 


\section{VALIDATION OF SELF-REPORTED ANTHROPOMETRICS}

feasible and group data or population averages are desired. However, due to reporting bias in overweight/obese individuals, reliance on BMI calculations based on erroneous weight and height values may result in misclassification of disease risk among individuals with greatest need.

\section{ACKNOWLEDGEMENTS}

This study was supported by a Research Development Grant from Bowling Green State University's College of Education and Human Development.

\section{REFERENCES}

1. Bes-Rastrollo M, Sabaté J, Jaceldo-Siegl K, Fraser GE. Validation of self-reported anthropometrics in the Adventist Health Study 2. BMC Public Health 11: 213-213, 2011.

2. Bonn SE, Trolle Lagerros Y, Bälter K. How valid are web-based self-reports of weight? J Med Internet Res 15(4): e52, 2013.

3. Bowling Green State University. BGSU fact book: Headcount enrollment with student characteristics by ethnicity. Office and Institutional Research, Bowling Green State University. 2012.

4. Brener ND, McManus T, Galuska DA, Lowry R, Wechsler H. Reliability and validity of self-reported height and weight among high school students. J Adolesc Health 32(4): 281-287, 2003.

5. Brozek J, Grande F, Anderson JT, Keys A. Densitometric analysis of body composition: Revision of some quantitative assumptions. Ann NY Acad Sci 110(1): 113-140, 1963.

6. Brunner Huber LR. Validity of self-reported height and weight in women of reproductive age. Matern Child Health J 11(2): 137-144, 2007.

7. Cash TF, Counts B, Hangen J, Huffine CE. How much do you weigh?: Determinants of validity of

International Journal of Exercise Science self-reported body weight. Percept Mot Skills 69(1): 248-250, 1989.

8. Connor Gorber S, Tremblay M, Moher D, Gorber B. A comparison of direct vs. self-report measures for assessing height, weight and body mass index: A systematic review. Obes Rev 8(4): 307-326, 2007.

9. Danubio M E, Miranda G, Vinciguerra MG, Vecchi E, Rufo F. Comparison of self-reported and measured height and weight: Implications for obesity research among young adults. Econ Hum Biol 6(1): 181-190, 2008.

10. Dor A, Ferguson C, Langwith C, Tan E. A heavy burden: The individual costs of being overweight and obese in the United States. George Washington University, School of Public Health and Health Services, Department of Health Policy. 2010.

11. Elgar FJ, Roberts C, Tudor-Smith C, Moore L. Validity of self-reported height and weight and predictors of bias in adolescents. J Adolesc Health 37(5): 371-375, 2005.

12. Engstrom J L, Paterson SA, Doherty A, Trabulsi M, Speer KL. Accuracy of self-reported height and weight in women: An integrative review of the literature. J Midwifery Womens Health 48(5): 338345, 2003.

13. Frankenfield DC, Rowe WA, Cooney RN, Smith JS, Becker D. Limits of body mass index to detect obesity and predict body composition. Nutrition 17(1): 26-30, 2001.

14. Gallagher D, Heymsfield SB, Heo M, Jebb SA, Murgatroyd PR, Sakamoto Y. Healthy percentage body fat ranges: An approach for developing guidelines based on body mass index. Am J Clin Nutr 72(3): 694-701, 2000.

15. Gil J, Mora T. The determinants of misreporting weight and height: The role of social norms. Econ Hum Biol 9(1): 78-91, 2011.

16. Heiss CJ, Gara N, Novotny D, Heberle H, Morgan L, Stufflebeam J, Fairfield M. Effect of a 1 liter fluid load on body composition measured by air displacement plethysmograhy and bioelectrical impedance. J Exerc Physiol Online 12(2): 1-8, 2009.

http://www.intjexersci.com 


\section{VALIDATION OF SELF-REPORTED ANTHROPOMETRICS}

17. Jacobson BH, DeBock DH. Comparison of body mass index by self-reported versus measured height and weight. Percept Mot Skills 92(1): 128-132, 2001.

18. Ladabaum U, Mannalithara A, Myer PA, Singh G. Obesity, abdominal obesity, physical activity, and caloric intake in U.S. adults: 1988-2010. Am J Med 127(8): 717-727, 2014.

19. Larsen JK, Ouwens M, Engels RCME, Eisinga R, van Strien T. Validity of self-reported weight and height and predictors of weight bias in female college students. Appetite 50(2-3): 386-389, 2008.

20. Leone RJ, Morgan AL, Ludy MJ. Patterns and composition of weight change in college freshmen. Coll Stud J 49(4): 553-564, 2015.

21. Ludy MJ, Leone RJ, Morgan AL Anthropometric indices lead to misclassification of health risk in metabolically obese normal weight female college freshmen. Unpublished Data. 2015.

22. McCrory MA, Molé PA, Gomez TD, Dewey KG, Bernauer EM. Body composition by airdisplacement plethysmography by using predicted and measured thoracic gas volumes. J Appl Physiol 84(4): 1475-1479, 1998.

23. Merrill RM, Richardson JS. Validity of selfreported height, weight, and body mass index: Findings from the National Health and Nutrition Examination Survey, 2001-2006. Prev Chronic Dis 6(4): A121-A121, 2009.

24. Morrell JS, Lofgren IE, Burke JD, \& Reilly RA. Metabolic syndrome, obesity, and related risk factors among college men and women. J Am Coll Health 60(1): 82-89, 2012.

25. National Heart, Lung, and Blood Institute. The practical guide: Identification, evaluation, and treatment of overweight and obesity in adults. US Department of Health and Human Services Public Health Service, National Institutes of Health. 2000.

26. Nawaz H, Chan W, Abdulrahman M, Larson D, Katz DL. Self-reported weight and height: Implications for obesity research. Am J Prev Med 20(4): 294-298, 2001.
27. Ode JJ, Pivarnik JM, Reeves MJ, Knous JL. Body mass index as a predictor of percent fat in college athletes and nonathletes. Med Sci Sports Exerc 39(3): 403-409, 2007.

28. Powell-Young YM. The validity of self-report weight and height as a surrogate method for direct measurement. Appl Nurs Res 25(1): 25-30, 2012.

29. Siri WE. Body composition from fluid spaces and density: Analysis of methods. In J. Brozek, A. Henschel (Eds.), Techniques for measuring body composition. National Academy of Sciences, National Research Council: 223-244, 1961.

30. Vandelanotte C, Duncan MJ, Hanley C, Mummery WK. Identifying population subgroups at risk for underestimating weight health risks and overestimating physical activity health benefits. J Health Psychol 16(5): 760-769, 2011.

31. Wane S, van Uffelen JGZ, Brown W. Determinants of weight gain in young women: A review of the literature. J Womens Health (Larchmt) 19(7): 1327-1340, 2010. 